\title{
Immunological heterogeneity in Type I diabetes: presence of distinct autoantibody patterns in patients with acute onset and slowly progressive disease
}

\author{
J. Seissler ${ }^{1}$, J.J.J. de Sonnaville ${ }^{2}$, N. G. Morgenthaler ${ }^{1}$, H. Steinbrenner ${ }^{1}$, D. Glawe ${ }^{1}$, U. Y. Khoo-Morgenthaler ${ }^{1}$, \\ M.S. Lan ${ }^{3}$, A. L. Notkins ${ }^{3}$, R.J. Heine ${ }^{2}$, W. A. Scherbaum ${ }^{1}$ \\ ${ }^{1}$ Diabetes Research Institute, University of Düsseldorf, Germany \\ ${ }^{2}$ Department of Endocrinology, University of Amsterdam, The Netherlands \\ ${ }^{3}$ Laboratory of Oral Medicine, NIH, Bethesda, USA
}

\begin{abstract}
Summary Type I diabetes mellitus may represent a heterogeneous disorder with a distinct pathogenesis in patients with young and adult onset of the disease. To investigate whether serological markers directed to different autoantigens have the potential to distinguish acute onset from slowly progressive Type I diabetes we analysed antibodies to tyrosine phosphatases IA-2/ICA512 (IA-2A) and IA-2 $\beta$ /phogrin (IA2 $\beta$ A), antibodies to GAD65 (GADA) and cytoplasmic islet cell antibodies (ICA) in a non-selected group of diabetic patients clinically classified as having Type I or Type II diabetes at diagnosis. Both IA$2 \mathrm{~A}$ and IA- $2 \beta \mathrm{A}$ were found to be positively associated with onset before the age of 20 years and the presentation of classical features of Type I diabetes. In Type I diabetes $56 \%(112 / 200)$ of patients were positive for IA-2A and $38 \%(76 / 200)$ for IA- $2 \beta$ A. In contrast, only 1 of $785(0.1 \%)$ patients with Type II diabetes had IA-2A and all of them were negative for IA- $2 \beta$ A $(p<0.001)$. Among the patients with Type II diabetes $7.6 \%(n=60)$ were ICA positive and $2.8 \%(n=22)$ had GADA suggesting the presence of slowly progressive Type I diabetes. GADA were found in 8 of $60(13.3 \%)$ ICA positive subjects which was lower than the percentage detected in patients
\end{abstract}

with acute onset of diabetes (115/157 73.2\%) $(p<0.001)$. Blocking of double antibody positive sera showed that only 3 of $8(37.5 \%)$ patients with slowly progressive diabetes had ICA restricted to GAD or IA-2 whereas ICA were completely inhibited in 12 of $20(60.0 \%)$ patients with Type I diabetes. Among 193 patients with Type II diabetes available for follow-up, $35 \%$ of ICA positives, $58 \%$ of GADA positives and $60 \%$ of those positive for both markers required insulin by 3 years. However, using strict criteria for the switch to insulin treatment the corresponding sensitivity of each marker was only low $(9 \%, 10 \%$ and $5 \%)$.

We show that clinical subtypes of Type I diabetes are associated with distinct humoral autoimmunity. IA-2A and GADA were associated with classical features of Type I diabetes whereas GADA and an uncharacterized ICA subspecificity indicate slowly progressive disease. [Diabetologia (1998) 41: 891-897]

Keywords Type I diabetes, slowly progressive Type I diabetes, autoantibodies, protein tyrosine phosphatase, glutamic acid decarboxylase, islet cell antibodies.
Received: 15 January 1998 and in revised form: 10 April 1998

Corresponding author: J. Seissler, M.D., Diabetes Research Institute, University of Duesseldorf, Auf'm Hennekamp 65, D-40225 Duesseldorf, Germany

Abbreviations: ICA, Islet cell antibodies; GADA, glutamic acid decarboxylase antibodies, IA-2A, protein tyrosine phosphatase IA- 2 antibodies; IA- $2 \beta$ A, protein tyrosine IA- $2 \beta$ antibodies.
According to the report of the Expert Committee on the Diagnosis and Classification of Diabetes Mellitus diabetes mellitus is classified in two major forms, Type I and Type II diabetes. Type I diabetes includes all forms of autoimmune-mediated and idiopathic beta-cell destruction leading to absolute insulin deficiency [1]. Depending on the severity of the autoimmune process and the extent of the beta-cell destruction, Type I diabetes may present a different clinical picture ranging from acute onset insulin-dependent 
diabetes with ketoacidosis to slowly progressing insulin deficiency where residual beta-cell function may be preserved for many years. The latter group is mainly found in adults who do not present the classical features of insulin-dependent diabetes mellitus at manifestation of the disease, thus misdirecting the classification to non insulin-dependent diabetes. Several studies suggest the presence of a slowly progressive beta-cell destruction in $3.2-14.3 \%$ of patients who were classified as Type II diabetes at diagnosis [2-8]. Such patients are generally characterized by the presence of residual insulin secretion at diagnosis followed by a progressive decrease of insulin secretory capacity and the development of insulin dependency over the course of their disease [2-4]. Evidence for an autoimmune pathogenesis was assessed by the demonstration of cytoplasmic islet cell antibodies (ICA) or antibodies to glutamic acid decarboxylase (GADA) or both in $56-95 \%$ of sera from patients with Type II diabetes who lost endogeneous insulin secretion 3-5 years after diagnosis [4, 5, 7-11].

Recently, two members of the protein tyrosine phosphatase family, termed IA-2/ICA512 and IA-2 $\beta$ / phogrin, have been identified as dominant target autoantigens in Type I diabetes. IA-2 antibodies (IA$2 \mathrm{~A})$ were detected in $50-73 \%$ of patients with juvenile Type I diabetes [12-15] and these antibodies were found to be strongly associated with the development of Type I diabetes in non-diabetic children and adolescents $[15,16]$. Comparison with cytoplasmic islet cell antibodies (ICA), the best validated to assess the risk for Type I diabetes, shows that the combination of antibodies to IA-2/ICA512 with GADA has the power to detect the majority of ICA positive individuals and $97-100 \%$ of subjects who progressed to overt diabetes $[16,17]$. These findings imply the possibility of replacing the laborious ICA test in screening programmes to identify subjects at risk for Type I diabetes. As yet it has not been known whether these results are applicable to slowly progressive Type I diabetes. One study reported on a low percentage of IA-2A (12\%) among 26 patients with slowly progressive Type I diabetes [18]. Population based data on the importance of antibodies to protein tyrosine phosphatases and their association with GADA or ICA are though not available.

In the present study, we show a heterogeneous autoimmune response in acute onset and slowly progressive Type I diabetes. We provide evidence that antibodies to protein tyrosine phosphatases are strongly associated with young age and the presence of classical features of Type I diabetes. In contrast, slowly progressive Type I diabetes is characterized by the appearance of GADA and an uncharacterized ICA subspecificity.

\section{Materials and methods}

Patients. Serum samples were obtained from 785 patients (age $64.3 \pm 12.3$, median 65.5 , range $40.0-96.0$ years) with Type II diabetes participating in a regional shared care project in Amsterdam [19]. The duration of diabetes was 0-44.9 years [mean $4.3 \pm 5.0$, median 1.9 years; 231 patients with recently diagnosed diabetes ( $<3$ months)]. Patients with secondary diabetes were excluded. After entry in the study the need for insulin treatment was monitored for up to 3 years after diagnosis. The decision to start insulin therapy was made individually based on failure of therapy with diet and oral hypoglycaemic agents which was defined as presence of poor metabolic control $\left(\mathrm{HbA}_{1 \mathrm{c}}>7.0 \%\right)$ despite good education and adherence to the prescribed treatment regimen. The presence of autoantibodies was used as a marker to distinguish patients with Type II diabetes from patients with an autoimmune-mediated form of diabetes.

Sera were also obtained from 200 consecutive patients with acute onset newly-diagnosed Type I diabetes (within 7 days of diagnosis) (mean age 19.4 \pm 9.4 , median 17.0 range 0.1-40.0 years). Diabetes was classified according to the World Health Organisation criteria [20]. Written informed consent was given by all patients participating in the study. The study was approved by the ethical committees of the centres participating in the study.

Detection of autoantibodies to protein tyrosine phosphatase $I A-2, I A-2 \beta$ and $G A D$. Autoantibodies to IA-2, IA- $2 \beta$ and GAD were determined using recombinant antigens in a 96well assay format as described [17]. Plasmid cDNA coding for the intracytoplasmic domains of human IA-2 (amino acids 603-980) (a kind gift from Dr. M. Christie, London, U.K.) [12], mouse IA-2 $\beta$ ic (amino acids 351--723) [21] or full length GAD65 (a kind gift from Dr. A Lernmark, Seattle, Washington) [22] was in vitro transcribed and translated in the presence of $\left[{ }^{35} \mathrm{~S}\right]$-methionine using a TNT rabbit reticulocyte lysate system (Promega, Madison, Wis., USA). Aliquots of radiolabelled proteins $(10000 \mathrm{cpm}$ for IA-2 and IA-2B or $20000 \mathrm{cpm}$ for GAD65) were incubated with $5 \mu \mathrm{l}$ serum in 96-well microtitre plates (Greiner, Nürtingen Germany) followed by adsorption of immunocomplexes with $20 \mu$ l Protein A Sepharose (v/ v). After extensive washing on 96-well filtration plates (Millipore, Bedford, Mass., USA) bound radioactivity was determined in a liquid scintillation counter and expressed in arbitrary units. The cut offs of the IA-2-, IA- $2 \beta$ - and GADA-assays were calculated as the 99th centile of normal control subjects (mean age 21.3 years, range 7-38 years, 3.4 IA-2A-U, 4.3 IA-2 $\beta$ A-U and 6.5 GADA-U). The inter-assay and intra-assay coefficient of variation were $9.8 \%$ and $7.8 \%(n=10)$ for antiIA- $2 \beta$. The assay for the detection of GADA was evaluated in the Second GAD Antibody Proficiency Program (values of $100 \%$ for sensitivity, specificity, validity and consistency). In the International Diabetes Combined Autoantibody Workshop our IA-2 antibody assay had a diagnostic sensitivity of $72.5 \%$ and a specificity of $96 \%$ for Type I diabetes.

Detection of cytoplasmic islet cell antibodies (ICA). Islet cell antibodies were detected by the indirect immunofluorescence test on unfixed cryostat sections of human pancreas from an organ donor with blood group 0 as described [23]. The detection limit of our assay was 2.5 Juvenile Diabetes Foundation units. In the 11th International Diabetes Workshop ICA Proficiency Program our laboratory achieved values of $100 \%$ for sensitivity, specificity, validity and consistency (Laboratory identification No. 116). 
Table 1. Prevalence of autoantibodies in patients classified as having Type II diabetes at diagnosis

\begin{tabular}{|c|c|c|c|c|c|c|c|c|c|}
\hline \multirow{2}{*}{$\begin{array}{l}\text { Duration } \\
\text { of diabetes } \\
\text { (years) }\end{array}$} & \multirow[t]{2}{*}{ Number } & \multirow[t]{2}{*}{ Female/male } & \multicolumn{2}{|l|}{ Age years } & \multirow[t]{2}{*}{ BMI } & \multicolumn{4}{|c|}{ Prevalence of autoantibodies } \\
\hline & & & mean & median & & $\mathrm{IA}-2 \beta \mathrm{A}$ & IA-2A & GADA & ICA \\
\hline$<2.0$ & 393 & $212 / 181$ & $63.4 \pm 12.8$ & 64.1 & $29.0 \pm 5.5$ & 0 & 0 & $8(2.0 \%)$ & $30(7.6 \%)$ \\
\hline $2.1-5.0$ & 156 & $91 / 65$ & $63.8 \pm 12.3$ & 64.0 & $28.9 \pm 4.8$ & 0 & $1(0.6 \%)$ & $8(5.1 \%)$ & $11(7.1 \%)$ \\
\hline $5.1-10.0$ & 140 & $88 / 52$ & $66.2 \pm 11.6$ & 67.1 & $28.2 \pm 5.0$ & 0 & 0 & $4(2.9 \%)$ & $11(7.9 \%)$ \\
\hline$>10.0$ & 96 & $61 / 35$ & $71.1 \pm 11.6$ & 73.3 & $27.6 \pm 3.9$ & 0 & 0 & $2(2.1 \%)$ & $8(8.3 \%)$ \\
\hline Total & 785 & $452 / 333$ & $64.3 \pm 12.3$ & 65.5 & $28.6 \pm 5.0$ & 0 & $1(0.1 \%)$ & $22(2.8 \%)$ & $60(7.6 \%)$ \\
\hline
\end{tabular}

Autoantibodies to IA-2ic (IA-2A), antibodies to IA- $2 \beta$ (IA-2 $\beta$ A), antibodies to glutamic acid decarboxylase (GADA), cytoplasmic islet cell antibodies (ICA), body mass index (BMI).

Table 2. Prevalence to autoantibodies in patients with new-onset Type I diabetes in different age groups

\begin{tabular}{|c|c|c|c|c|c|c|}
\hline \multirow{2}{*}{$\begin{array}{l}\text { Age at onset } \\
\text { (years) }\end{array}$} & \multirow[t]{2}{*}{ Number } & \multirow[t]{2}{*}{ Female/male } & \multicolumn{4}{|c|}{ Prevalence of autoantibodies } \\
\hline & & & $\mathrm{IA}-2 \beta \mathrm{A}$ & IA-2A & GADA & ICA \\
\hline \multicolumn{7}{|c|}{ Type I diabetes } \\
\hline $0-5$ & 8 & $4 / 4$ & $4(50.0 \%)$ & $6(75.0 \%)^{5}$ & $2(25.0 \%)^{7}$ & $7(87.5 \%)$ \\
\hline $6-10$ & 22 & $12 / 10$ & $11(50.0 \%)^{1}$ & $15(68.2 \%)^{5}$ & $17(77.3 \%)$ & $19(86.4 \%)$ \\
\hline $11-15$ & 52 & $29 / 13$ & $27(51.9 \%)^{2,3}$ & $40(76.9 \%)^{6,3}$ & $36(69.2 \%)$ & $44(84.6 \%)$ \\
\hline $16-20$ & 41 & $21 / 20$ & $18(43.9 \%)^{4}$ & $25(70.0 \%)^{3}$ & $29(70.7 \%)$ & $33(80.5 \%)$ \\
\hline $21-25$ & 24 & $9 / 15$ & $6(25.0 \%)$ & $11(45.8 \%)$ & $15(62.5 \%)$ & $15(62.5 \%)$ \\
\hline $26-30$ & 22 & $9 / 13$ & $5(22.7 \%)$ & $8(36.4 \%)$ & $13(59.1 \%)$ & $15(68.2 \%)$ \\
\hline $31-40$ & 31 & $18 / 20$ & $5(16.1 \%)$ & $7(22.6 \%)$ & $19(61.3 \%)$ & $24(77.4 \%)$ \\
\hline Total & 200 & $102 / 98$ & $76(38.0 \%)$ & $112(56.0 \%)$ & $131(65.5 \%)$ & $157(78.5 \%)$ \\
\hline
\end{tabular}

Autoantibodies to IA-2ic (IA-2A), antibodies to IA- $2 \beta$ (IA$2 \beta \mathrm{A})$, antibodies to glutamic acid decarboxylase (GADA), cytoplasmic islet cell antibodies (ICA).

Blocking studies. Blocking studies of ICA were performed in selected sera from patients classified as having Type I diabetes $(20$ sera GADA or IA-2A positive or both, 5 sera with ICA only) or Type II diabetes ( 8 sera with GADA or IA$2 \mathrm{~A}$ or both, 5 sera with ICA only) at diagnosis. Sera were diluted to an ICA level of 10 Juvenile Diabetes Foundation units with phosphate buffered saline alone or containing a mixture of human recombinant GAD65 and IA-2ic (final concentration $2.5 \mu \mathrm{g}$ each). After $12 \mathrm{~h}$ at $4{ }^{\circ} \mathrm{C}$ ICA were determined by the indirect immunofluorescence test as described.

Statistical analysis. Values are given as mean \pm SD unless otherwise indicated. The significance of differences between observations was tested using the the chi-square test with Yates' correction, Fisher's exact test, or Mann-Whitney test where appropriate. $P$ values were corrected for multiple comparisons. The significance of correlations between antibody levels was tested by Spearman rank correlation. Statistical tests were performed by the Statistical Package for Social Sciences (SPSS, Chicago, Ill., USA).

\section{Results}

Prevalence of autoantibodies in patients with adult onset diabetes. The clinical and immunological features of patients are listed in Tables 1 and 2. ICA and GADA were identified as the dominant humoral markers in patients classified as having Type II diabetes at diagnosis. Among 785 patients with Type II diabetes, $60(7.6 \%)$ were positive for ICA (mean ICA
${ }^{1} p<0.02$ vs $31-40$ years, ${ }^{2} p<0.05$ vs $21-30$ years, ${ }^{3} p<0.005$ vs $31-40$ years, ${ }^{4} p<0.05$ vs $31-40$ years, ${ }^{5} p<0.01$ vs $31-40$ years, ${ }^{6} p<0.01$ vs $21-30$ years, ${ }^{7} p<0.05$ vs $6-20$ years

level $20 \pm 25$, range 5-160 JDF-U) and 22 had GADA $(2.8 \%$ ) (mean level $41 \pm 28$, range 7-99 GADA-U) suggesting the presence of slowly progressive Type I diabetes. Only $1(0.13 \%)$ patient with Type II diabetes had IA-2A and all sera were IA-2 $\beta$ A negative $(p<0.001)$. Thus, antibodies to IA2 and IA- $2 \beta$ did not significantly differ from control subjects. In contrast, 26 out of $77(33.8 \%)$ patients aged $21-40$ years with Type I diabetes tested positive for IA-2A and $16(20.8 \%)$ subjects had IA-2 $\beta$ A $(p<0.001)$. Comparison of antibody frequencies in patients with Type I diabetes showed an inverse correlation between the presence of IA- $2 \beta$ A and IA-2A compared with age (Table 2 ). The prevalences of both IA-2A and IA-2 $\beta$ A were higher in the age group $0-20$ years $(69.9 \%$ and $48.8 \%)$ as compared with subjects aged $21-30$ years $(41.3 \%$ and $23.9 \%)$ $(p<0.005)$ or subjects above 30 years of age $(22.6 \%$ and $16.1 \%)(p<0.001)$. In contrast, GADA were less frequent in patients aged 0-5 years compared with the group above 5 years of age $(p<0.05)$. GADA as well as ICA levels were not significantly correlated with age. In Type II diabetes the frequency of ICA, but not GADA, was increased in subjects who had a BMI under $25 \mathrm{~kg} / \mathrm{m}^{2}(12.4 \%)$ compared with patients with BMI $25 \mathrm{~kg} / \mathrm{m}^{2}$ or more $(6.3 \%)$ $(p<0.01)$. There was no sex and age difference between antibody positive and negative patients classified as having Type I or Type II diabetes. 
Table 3. Competition experiments in GADA and/or IA-2A positive patients classified as Type I or Type II diabetes

\begin{tabular}{lrl}
\hline ICA positive subjects & number & $\begin{array}{l}\text { ICA staining } \\
\text { blocked by GAD65 } \\
\text { and IA-2ic }\end{array}$ \\
\hline Patients classified as Type I diabetes & \\
GADA and/or IA-2A positive & 20 & $12(60.0 \%)^{1}$ \\
GADA and IA-2A negative & 5 & 0 \\
Patients classified as Type II diabetes & \\
GADA and/or IA-2A positive & 8 & $3(37.5 \%)$ \\
GADA and IA-2A negative & 5 & 0
\end{tabular}

Sera were preincubated with a mixture of GAD65 and IA-2ic and analysed for cytoplasmic islet cell antibodies (ICA) by indirect immunofluorescence test. ${ }^{1} p=$ NS vs Type II diabetes

Correlation of autoantibodies. In patients with Type I diabetes a significant correlation of ICA with IA-2A, IA- $2 \beta A$ and GADA was observed. ICA were associated with the presence, levels and numbers of antibodies directed to defined islet antigens. Combined detection of IA-2A and GADA identified $96.1 \%$ of ICA positive patients with Type I diabetes aged 0-20 and $92.6 \%$ aged $21-40$ years. Out of 76 IA- $2 \beta$ A positives $73(96.1 \%)$ were positive for IA-2A. In the three cases with IA- $2 \beta \mathrm{A}$ in the absence of IA- $2 \mathrm{~A}$ only low levels of IA-2 $\beta$ A (4.4-5.0 IA- $2 \beta$-U) were present. Competition experiments showed that the majority of IA- $2 \beta$ A positive sera $(93 \%)$ were completely blocked by preincubation with IA-2 suggesting the presence of cross-reactive antibodies irrespective of age or clinical presentation (data not shown).

Heterogeneous reactivity of ICA. A marked difference between acute onset and slowly progressive Type I diabetes was found when ICA subspecificities were analysed in blocking experiments (Table 3). Single ICA positivity was observed in 52 of $60(86.7 \%)$ antibody positive sera from patients classified as having Type II diabetes but in only 8 of $157(5.1 \%)$ patients with Type I diabetes $(p<0.001)$. Screening for additional insulin autoantibodies (IAA) detected by competitive radioimmunoassay showed that only 2 of 60 ICA positive sera from patients with Type II diabetes had positive IAA (1 serum positive for ICA, GADA and IA-2A, one serum positive for ICA only) (data not shown). In patients with Type I diabetes ICA staining was completely blocked in $60.0 \%$ (12 of 20) of sera positive for GADA or IA-2A or both by preincubation with a mixture of GAD65 and IA-2 (Fig. 1). In contrast, ICA reactivity was inhibited in only 3 of $8(37.5 \%)$ GADA or IA-2A positive sera from patients with slowly progressive Type I diabetes. Including the 52 single ICA positive sera from patients with Type II diabetes only 3 of $60(5.0 \%)$ patients with slowly progressive Type I diabetes display ICA reactivity restricted to GAD or IA-2. These data clearly show that in patients with slowly progressing autoimmune diabetes the majority of ICA are directed to an uncharacterized target antigen.

Follow-up investigation. Follow-up data were available from 193 patients 3 years after entry to the study. Insulin therapy was initiated in 57 of $169(33.7 \%)$ antibody negative subjects and in 10 of $24(41.7 \%)$ antibody positive patients, of whom $6(25.0 \%)$ were found positive for ICA and 7 (29.2\%) for GADA (Table 4). IA-2A were detected in only one individual who was switched to insulin therapy 2 years after diagnosis. ICA, GADA and IA-2A possess a high specificity $(91.3-100 \%)$ for the prediction of insulin requirement among an non-selected group of patients with Type II diabetes. Due to the use of strict metabolic criteria for starting with insulin therapy the corresponding sensitivities of these markers were only low (1.5-14.9\%) (Table 4).

\section{Discussion}

Patients with autoimmune-mediated diabetes may have a variable clinical presentation at the manifestation of the disease suggesting differences in the underlying pathogenetic processes. To define common and distinct autoimmune features in clinical subtypes of Type I diabetes we analysed autoantibody patterns in a large cohort of patients classified as having Type I or Type II diabetes at diagnosis. We show a clear difference of humoral autoimmunity in patients with acute onset or slowly progressive Type I diabetes. Among 785 unselected patients classified as having Type II diabetes only 1 had IA-2A and no serum was positive for IA- $2 \beta$ A whereas $56 \%$ and $38 \%$ of patients with Type I diabetes were positive for the respective antibodies. Subdividing the patients with Type I diabetes according to age shows that the IA$2 \mathrm{~A}$ and IA- $2 \beta \mathrm{A}$ are inversely correlated with age, ranging from $70 \%$ and $49 \%$ in patients below 10 years to $22.6 \%$ and $16.1 \%$ in diabetic patients above 30 years of age, respectively. Our observations suggest that autoimmunity to PTPs reflect a severe beta-cell destruction leading to manifestation of the disease early in life or to acute onset of diabetes and insulin dependency when present in older individuals. This is consistent with studies in prediabetic subjects where rapid progression to overt diabetes was described in subjects at risk for Type I diabetes positive for IA-2A as compared with subjects positive only for ICA or GADA $[16,24,26]$. As described for the $37 \mathrm{kD} / 40 \mathrm{kD}$ antibodies and IA-2A, both the prevalence and levels of IA- $2 \mathrm{~A} \beta$ were closely associated with IA-2A and both were positively correlated with ICA but not with GADA [26-28]. In agreement with these studies we found only a small fraction of sera $(n=3)$ containing antibodies which exclusively rec- 


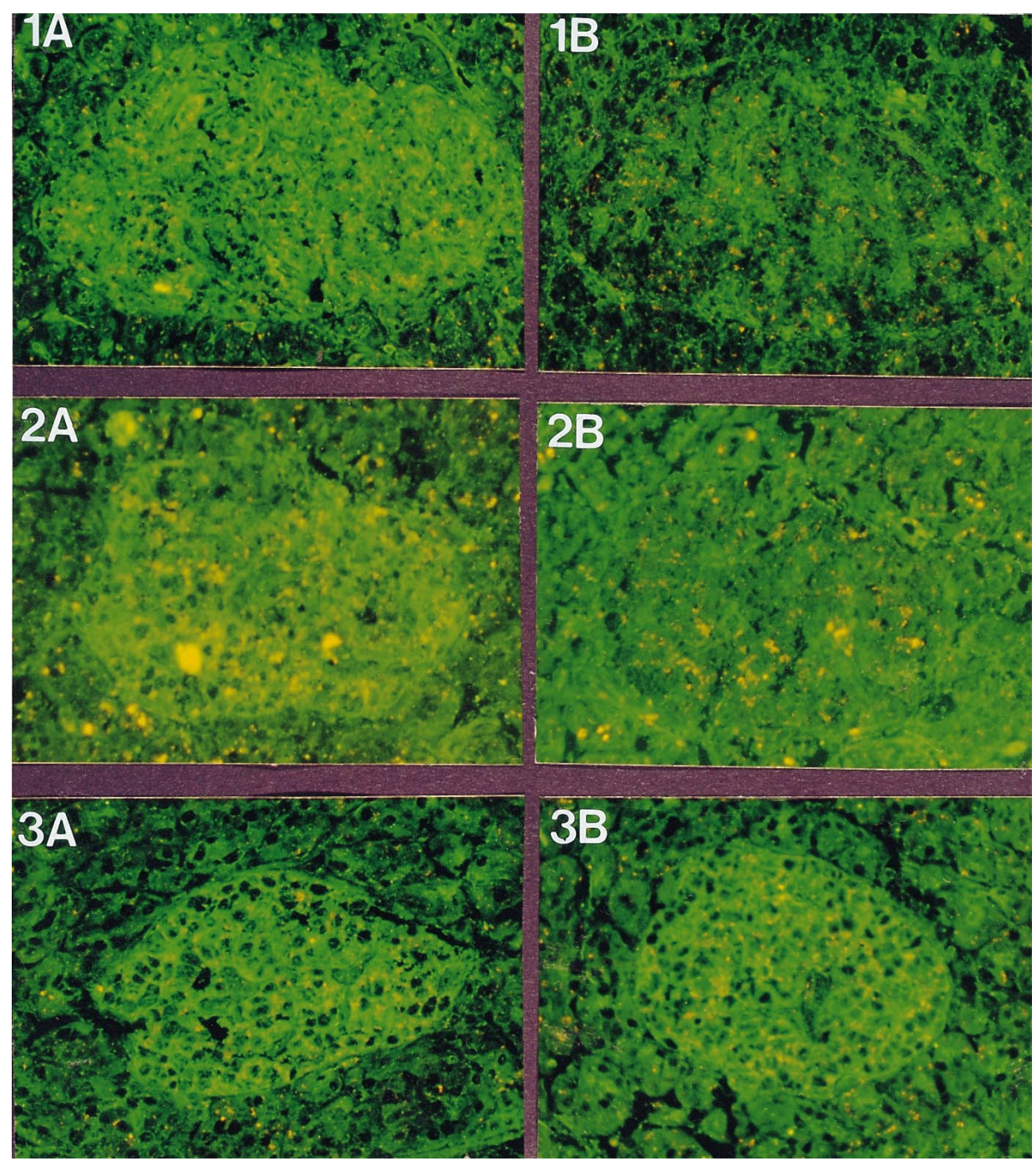

Fig. 1A,B. Analysis of ICA subspecificities on cryostat sections of human pancreas by preincubation of sera from patients with Type II diabetes (A) using phosphate buffered saline and (B) using a mixture of GAD65 and IA-2ic. GADA + /IA-2A + serum (1), GADA + /IA-2A- serum $(2,3)$

ognized IA-2 $\beta$. Competition experiments showed no difference in the reactivity of sera from young and adult onset diabetic patients in that the majority of IA- $2 \beta$ A could be blocked by preabsoption with IA-2 (data not shown). This supports the hypothesis that about two thirds of IA-2A positive patients develop cross-reactive autoantibodies [21, 28]. The clinical and pathogenetic importance of the heterogeneous antibody response directed to common and distinct epitopes of IA- 2 and IA- $2 \beta$ remains as yet unclear. However, it is of interest to note that IA-2A and IA$2 \beta \mathrm{A}$ double positive subjects did not differ significantly from subjects who possess either IA-2A or IA- $2 \mathrm{~A} \beta$ only with respect to age, gender, and the presence of additional ICA or GADA.
In agreement with previous studies ICA and GADA were found not only to be associated with Type I diabetes but also with patients who had clinical signs of Type II diabetes at diagnosis. Both the prevalence of ICA $(7.6 \%)$ and GADA $(2.8 \%)$ were in the lower range compared with previous studies which described ICA in $3.2-14.3 \%$ and GADA in $1.1-9.0 \%$ among non-selected patients with Type II diabetes $[2-5,7,8,29]$. This finding may be explained by the fact that we studied older patients (median 65.5 years) from a group with a lower incidence of Type I diabetes [30] suggesting a lower incidence of slowly progressive Type I diabetes compared with previous studies from Finland and the United Kingdom.

To evaluate further differences in the autoimmune response between acute onset and slowly progressive Type I diabetes we carried out blocking studies in ICA positive sera. Our data confirm recent findings that IA-2 and GAD are the dominant target of ICA in patients with classical features of Type I diabetes $[31,32]$, but also support the hypothesis that this approach is not sufficient to identify all patients with 
Table 4. Development of insulin requirement in patients classified as having Type II diabetes during 3 years of follow-up in relation to antibody status

\begin{tabular}{|c|c|c|c|c|c|}
\hline \multirow[t]{2}{*}{ Antibody status } & \multirow[t]{2}{*}{ Number } & \multicolumn{2}{|c|}{ Therapy after 3 years } & \multirow[t]{2}{*}{ Sensitivity } & \multirow[t]{2}{*}{ Specificity } \\
\hline & & Oral & Insulin & & \\
\hline ICA positive & 17 & 11 & $6(35.2 \%)$ & $9.0 \%$ & $91.3 \%$ \\
\hline GADA positive & 12 & 5 & $7(58.3 \%)$ & $10.5 \%$ & $96.0 \%$ \\
\hline IA- $2 \mathrm{~A}$ positive & 1 & 0 & $1(100 \%)$ & $1.5 \%$ & $100 \%$ \\
\hline ICA and GADA positive & 5 & 2 & $3(60.0 \%)$ & $4.5 \%$ & $98.4 \%$ \\
\hline ICA or GADA positive & 24 & 14 & $10(41.7 \%)$ & $14.9 \%$ & $88.9 \%$ \\
\hline Antibody negative & 169 & 112 & $57(33.7 \%)^{1}$ & & \\
\hline
\end{tabular}

${ }^{1} p=$ NS vs antibody positive patients

adult onset autoimmune diabetes [33]. In sharp contrast to patients with Type I diabetes, where $95 \%$ of ICA positive subjects had GADA or IA-2A or both, we found that in patients with slowly progressive Type I diabetes $13.3 \%$ of ICA positive subjects had GADA or IA-2A and only 3 sera had ICA restricted to GAD65 and IA-2. On the basis of our data, it cannot be decided whether those ICA recognize one or several autoantigens described in Type I diabetes, e.g. gangliosides, ICA69, carboxypeptidase $\mathrm{H}$ and Glima 38, or is directed to a novel autoantigen. Further studies are required to answer this question. Including the sera positive for ICA only, it is important to emphasize that the non-GAD/non-IA-2 ICA reactivity was significantly more frequent among patients with slowly progressive disease (95\%) compared with patients with acute onset Type I diabetes (less than $50 \%$ ).

We also studied the value of autoantibodies for the prediction of insulin requirement. Follow-up investigation showed that the presence of ICA, GADA or both markers had a high specificity (91, 96 and $98 \%$ ) but only a low sensitivity $(9,10$ and $5 \%)$ to indicate future need for insulin treatment. The specificities of single and combined autoantibodies that were observed are in line with previous reports but the corresponding sensitivities seem to be lower than described before [4-8]. This disagreement could, at least in part, be explained by the application of strict target $\mathrm{HbA}_{1 \mathrm{c}}$ target values to switch treatment to insulin therapy. Furthermore, we investigated an older group of patients compared with previous studies [4-7]. In line with our results, Turner et al. [8] recently reported on a decreased sensitivity of ICA and GADA for the prediction of insulin treatment and a slower progression to insulin dependency in patients aged 45-65 years as compared with younger patients with Type II diabetes. It is important to note, however, that screening for both ICA and GADA can provide information on an autoimmune-mediated diabetes in older subject which could be useful for the selection of diabetes therapy.

In conclusion, our data provide further evidence for the concept of heterogeneity of Type I diabetes. We demonstrate that clinical subtypes of autoim- mune diabetes are associated with the appearance of different autoantibodies which may reflect distinct courses of the autoimmune response correlated with rapid or slowly progressive destruction of the betacells. Since slowly progressive Type I diabetes was characterized by the presence of GADA and a still unidentified ICA, subspecificity screening for autoimmune diabetes in adults has to include both GADA and ICA. These findings could be important for accurate classification of diabetes, identification of subjects who can benefit from early insulin therapy and selection of patients for future intervention trials to delay or prevent autoimmune beta-cell destruction.

Acknowledgements. We thank Drs. Å. Lernmark, A.E. Karlsen and C.E. Grubin for the gift of human GAD65 cDNA and M. Christie for providing the IA-2 cDNAclone. We gratefully acknowledge M. Seubert and L. Moser for collecting the sera and all patients and physicians who agreed to participate in the study. The study was supported by the Deutsche Forschungsgemeinschaft Se 725/1-2, the Deutsche Diabetes Gesellschaft (WAS, JS), and the Juvenile Diabetes Foundation International (grant number 192932).

\section{References}

1. The Expert Committee on the Diagnosis and Classification of Diabetes Mellitus (1997) Report on the expert committee on the diagnosis and classification of diabetes mellitus. Diabetes Care 20: 1183-1197

2. Irvine WJ, Sawers SA, Feek CM, Prescott RJ, Duncan LJP (1979) The value of islet cell antibody in predicting secondary failure of oral hypoglycaemic agent therapy in diabetes mellitus. J Clin Lab Immunol 2: 23-26

3. Groop LC, Bottazzo GF, Doniach D (1986) Islet cell antibodies identify latent Type I diabetes in patients aged 35-75 years at diagnosis. Diabetes 35: 237-241

4. Gottsäter A, Landin-Olsson M, Fernlund P, Lernmark A, Sundkvist G (1993) $\beta$-cell function in relation to islet cell antibodies during the first 3 years after clinical diagnosis of diabetes in Type II diabetic patients. Diabetes Care 16: 902-910

5. Niskanen LK, Tuomi T, Karjalainen J Groop LC, Uusitupa MI (1995) GAD antibodies in Type I diabetes. Diabetes Care 12: 1557-1565

6. Rowley MJ, Mackay IR, Chen QY, Knowles WJ, Zimmet PZ (1992) Antibodies to glutamic acid decarboxylase dis- 
criminate major types of diabetes mellitus. Diabetes 41 : $548-551$

7. Kobayashi T, Nakanishi K, Okubo M, Murase T, Kosaka K (1996) GAD antibodies seldom disappear in slowly progressive IDDM. Diabetes Care 19: 1031

8. Turner R, Stratton I, Horton V et al. (1997) UKPDS 25: autoantibodies to islet-cell cytoplasm and glutamic acid decarboxylase for prediction of insulin requirement in Type II diabetes. Lancet 350: 1288-1293

9. Groop L, Miettinen A, Groop PH, Meri S, Koskimies S, Bottazzo GF (1988) Organ-specific autoimmunity and HLA-DR antigen as markers for $\beta$-cell destruction in patients with Type II diabetes. Diabetes 37: 99-103

10. Zimmet PZ, Tuomi T, Mackay IR et al. (1994) Latent autoimmune diabetes mellitus in adults (LADA): the role of antibodies to glutamic acid decarboxylase in diagnosis and prediction of insulin dependency. Diabet Med 11: 299-303

11. Tuomi T, Groop LC, Zimmet PZ, Rowley J, Knowles W, Mackay IR (1993) Antibodies to glutamic acid decarboxylase reveal latent autoimmune diabetes mellitus in adults with a non-insulin-dependent onset of disease. Diabetes 42: 359-362

12. Payton MA, Hawkes CJ, Christie MR (1995) Relationship of the 37,000- and 40,000Mr tryptic fragments of islet antigens in insulin-dependent diabetes to the protein tyrosine phosphatase-like molecule IA-2 (ICA512). J Clin Invest 96: 1506-1511

13. Lan MS, Wasserfall C, Maclaren NK, Notkins AL (1992) IA-2, a transmembrane protein of the tyrosine phosphatase family, is a major autoantigen in insulin-dependent diabetes mellitus. Proc Natl Acad Sci USA 93: 6367-6370

14. Morgenthaler N, Seissler J, Achenbach P et al. (1997) Antibodies to the tyrosine phosphatase-like protein IA-2 are highly associated with Type I diabetes, but not with autoimmune endocrine disease or Stiff Man syndrom. Autoimmunity 25: 202-212

15. Wiest-Ladenburger U, Hartmann R, Hartmann U, Berling K, Boehm BO, Richter W (1997) Combined analysis and single-step detection of GAD65 and IA-2 autoantibodies in Type I diabetes can replace the histochemical islet cell antibody test. Diabetes 46: 565-571

16. Verge CF, Gianani R, Kawasaki E et al. (1996) Prediction of Type I diabetes in first degree relatives using a combination of Insulin, GAD, and ICA512bdc/IA-2 autoantibodies. Diabetes 45: 926-933

17. Seissler J, Morgenthaler NG, Achenbach P et al. (1996) Combined screening for antibodies to IA-2 and antibodies to glutamic acid decarboxylase in first degree relatives of patients with Type I diabetes. Diabetologia 39: 1351-1356

18. Kasuga A, Ozawa Y, Maruyama T, Ishihara T, Amemiya S, Saruta T (1997) Autoantibodies against ICA512 did not improve test sensitivity for slowly progressive IDDM. Diabetes Care 20: 679-680

19. Sonnaville JJJ de, Bouma M, Colly LP, Deville W, Wijkel D, Heine RJ (1997) Sustained good glycaemic control in NIDDM patients by implementation of structured care in general practice: 2-year follow-up study. Diabetologia 40: $1334-1340$

20. World Health Organisation Study Group on Diabetes mellitus (1985) Technical report series No. 727, WHO, Geneva

21. Lu J, Li Q, Xie H et al. (1996) Identification of a second transmembrane protein tyrosine phosphatase, IA- $2 \beta$, as an autoantigen in insulin-dependent diabetes mellitus: precursor of the $37-\mathrm{kDa}$ tryptic fragment. Proc Natl Acaol Sci USA 93: 2307-2311

22. Karlsen AE, Hagopian WA, Grubin CE et al. (1991) Cloning and primary structure of a human islet isoform of glutamic acid decarboxylase from chromosome 10. Proc Natl Acad Sci USA 88: 8337-8341

23. Scherbaum WA, Mirakian R, Pujol-Borrell R, Dean BM, Bottazzo GF (1986) Immunochemistry in the study and diagnosis of organ-specific autoimmune disease. In: Polak JM, Van Noorden S (eds) Immunochemistry. Modern methods and applications. Wright, Bistrol, pp 456-476

24. Seissler J, Hering B, Richter W et al. (1993) Antibodies to the $\mathrm{Mr} 64,000(64 \mathrm{~K})$ protein in islet cell antibody positive non-diabetic individuals indicate high risk for impaired beta-cell function. Diabetologia 35: 550-554

25. Bingley PJ, Christie MR, Bonifacio E et al. (1994) Combined analysis of autoantibodies improves prediction of Type I diabetes in islet cell antibody-positive relatives. Diabetes 43: 1304-1310

26. Christie M, Genovese S, Cassidy D et al. (1994) Antibodies to islet $37 \mathrm{k}$ antigen, but not to glutamate decarboxylase, discriminate rapid progression to Type I diabetes in endocrine autoimmunity. Diabetes 43: 1254-1259

27. Kawasaki E, Eisenbarth GS, Wasmeier C, Hutton JC (1996) Autoantibodies to protein tyrosine phosphataselike proteins in Type I diabetes. Overlapping specificities to phogrin and ICA512/IA-2. Diabetes 45: 1344-1349

28. Hawkes CJ, Wasmeier C, Christie MR, Hutton JC (1996) Identification of the $37 \mathrm{k}$-antigen in insulin-dependent diabetes as a tyrosine phosphatase like protein (phogrin) related to IA-2. Diabetes 45: 1187-1192

29. Ruige JB, Batstra MR, Aanstoot HJ et al. (1997) Low prevalence of antibodies to GAD65 in a 50- to 74- yearold general Dutch population. Diabetes Care 20: $1108-1110$

30. Green A, Gale EAM, Patterson CC, Eurodiab Ace Study Group (1992) Incidence of childhood-onset insulin-dependent diabetes mellitus. Lancet 339: 905-907

31. Richter W, Seissler J, Northemann W, Wolfahrt S, Meinck HM, Scherbaum WA (1993) Cytoplasmic islet cell antibodies recognize distinct islet antigens in Type I diabetes but not in Stiff Man Syndrome. Diabetes 42: 1642-1648

32. Myers MA, Rabin DU, Rowley MJ. (1995) Pancreatic islet cell cytoplasmic antibody in diabetes is represented by antibodies to islet cell antigen 512 and glutamic acid decarboxylase. Diabetes 44: 1290-1295

33. Lohmann T, Seissler J, Verlohren HJ et al. (1997) Distinct genetic and immunological features in patients with insulin-dependent diabetes below and above age 40 at onset. Diabetes Care 20: 524-529 